\title{
Profitability Analysis of Workflow Management Systems
}

\author{
Horst Gruber \\ Raiffeisen Informatik GmbH \\ Vienna, Austria \\ horst.gruber@r-it.at
}

\author{
Christian Huemer \\ Institute of Software Technology and Interactive \\ Systems \\ Vienna University of Technology \\ Vienna, Austria \\ huemer@big.tuwien.ac.at
}

\begin{abstract}
Workflow technology promises an increase in efficiency in the execution of business processes. The technology is widely accepted, but often the high costs exceed the promised benefits. Thus, it is desirable to calculate the profitability prior to investing into workflow technology. After an investment into workflow management systems (WFMS), it has to be verified whether the expected benefits have been realized or not. In this paper we present a method that covers both, the cost-benefit-ratio calculations specially customized for WFMS and the calculation of the realized savings. The profitability analysis is based on simple measurable performance indicators that consider the tangible calculation of costs as well as the quantitative and qualitative benefits. Long time practical experience in implementing and operating workflow management supported the design of the method. The method presented in this paper has been successfully used in the IT company of a banking corporation.
\end{abstract}

Keywords: Business Process Management, Workflow Management, Profitability Analysis, Cost Benefit Calculation

\section{Motivation}

In practice, the IT-support of business processes is often interwoven into function-oriented software, which implements functions or parts of functions of a business process. More advanced process-oriented software is necessary for an integrated support of a process by IT [29]. Process-oriented software enables the automation of business processes with the target to increase the efficiency of a business process. In this paper we consider the automation of business processes by Workflow Management Systems (WFMS). WFMS are a special type of process-oriented software that defines, manages and executes workflows through the execution of software whose order of execution is driven by a computer representation of the business process logic [28].

Workflow management is by definition an interdisciplinary topic that requires knowledge in computer science, business informatics and business administration. In practice, workflow management is usually dominated by technologists in companies. They start off by selecting a preferred tool from a pure technology point of view. A tool is quite often selected without matching the existing business requirements. Thereby, the cost-benefit ratio is neglected. Accordingly, this approach often leads to high costs that exceed the promised benefits of WFMS.
The evaluation of the cost-benefit relation is a prerequisite to enable a management decision for an investment in automation of business processes by WFMS. Accordingly, the planning phase of a WFMS implementation must be based on a more holistic view. First, an evaluation of appropriate business processes for automation by WFMS has to be executed [11]. Than a tool evaluation based on the selected processes has to follow [13][3][5]. At last the profitability analysis justifies the decision in the investment of supporting the selected processes by the selected WFMS tool. In this paper we concentrate on the profitability analysis.

The profitability analysis scrutinizes the relation between costs and benefits. The costs of automation of business processes are determined. The potential types of benefits, discovered in [11], are not quantified at this time. Thus, the calculation of the quantitative benefit is part of the profitability analysis. The relation between costs and quantifiable benefits also considering the qualitative benefit enables a management decision for an investment in WFMS. Our method for the profitability analysis targets a transparent, simple usable and revisable procedure for the calculation of the cost-benefit-ratio of automating business processes by WFMS. An investment is only recommended if the expected benefits exceed the expected costs. We demonstrate that our method produces consistent, transparent, and reproducible results by validating it in the IT Company of a banking corporation.

\section{RESEARCH QUESTIONS AND RESEARCH METHODOLOGY}

Based on the motivation in section I our research has been guided by two research questions: (RQ1) how can costs and quantifiable benefits of automation by WFMS be calculated and (RQ2) how can a decision to an investment in workflow management regarding quantitative and qualitative benefits be reached?

The analysis and discussion of these research questions is reflected by the structure of this paper. Section III attends the related work. Section IV elaborates on the proposed method comprising the profitability analysis. Subsection A opens an overview of the method. The cost-benefit calculation (RQ1) and the decision finding (RQ2) are explained in detail in subsection $\mathrm{B}$. In subsection $\mathrm{C}$ we present the findings of executing the framework in an IT company of a banking 
corporation. The paper concludes with a summary and an outlook in Section V.

This section also illustrates the design of our research. Our research methodology for the profitability analysis included three steps. In a first step, we did a conceptual research by a literature study. Existing approaches and methods for profitability analyzes were scrutinized. In a second step the evaluation approach was concretized and the evaluation method (answering RQ1-2) was fixed due to our long experience in automation of business processes by WFMS. In a third step we tested the method on five selected business processes in the IT Company of a banking corporation.

\section{RELATED WORK}

The literature concerning the profitability analysis in the third module distinguishes between two different major evaluation approaches. Firstly, appraisals of IT investments primarily consider costs and benefits. Costs can be defined as the total expenses for goods or services including time, money and labour. The literature differentiates between different cost types (e.g. internal/external costs, direct/indirect, fixed/variable, [1][12]). In this paper we use the cost categories for Information Technology introduced by Becker et al [4] which will be explained in detail further down. 'Benefit' is a term used to indicate an advantage, profit, or gain attained by an individual or an organization. The benefit of an investment is divided into a quantifiable (tangible benefit [16]) and a qualified (not quantifiable benefit, also called intangible benefit [16] or imponderability [4]) benefit. A quantifiable benefit like direct savings or an increase in revenues [16][4] can be measured. A qualifiedly benefit like the increase of transparency of the performance of a process and increasing responsiveness of the process status cannot be measured [14]. But these (qualified) benefits are advantages that influence an overall evaluation and decision. For the evaluation of investments other criteria can be used like the evaluation of risks [15]. But we hold the opinion that these criteria are insignificant for an evaluation of WFMS.

Numerous investment management approaches can be found in literature [16][19][12]. All these approaches can be differentiated according to various aspects. Traditional investment calculations are classified as either static or dynamic calculation methods. Static investment calculations [19][12] are based on costs and benefits without considering the time value of money (only one time period taken into consideration). The cost comparison approach (costs of different alternatives are compared), the profit comparison approach (profits of different alternatives are compared), the profitability calculation (similar to the return on investment [9] - the average yearly interest rate is calculated), and the payback period (the period of return is calculated - similar to the break even analysis [16]) belong into this category. Dynamic investment calculations [19][12] are also based on costs and benefits but consider the current value of money (several time periods are observed) by comparing the initial cash outflows (or expenses) prior to an investment with the expected cash inflows (or revenues) of the investment. The complexity of these approaches is due to the difficulty of forecasting the inflows and outflows. The net present value approach (the net present value of an investment at the beginning of the expected useful economic life is calculated [16]), the internal interest rate (the internal rate in case of a net present value of zero, similar to the internal rate of return [16]) and the amount of annuity (the profit of a period is calculated) fall into this category.

Of particular interest for our approach are processoriented evaluation methods which evaluate the operational work and business process performance. Particularly the following approaches deal with the time which employees save with the help of information technologies. The times savings times salary (TSTS) [25][26] approach is based on the assumption that an employee's salary is a measure of his "contribution" or "value" to an organization. It has the objective to estimate the working hours an IT investment (e.g., a new information system) will save, and then to multiply these hours with the salaries of all affected employees. The TSTS approach is easy to implement and therefore often used in practice. Due to its assumptions, this approach has some disadvantages. Firstly, it is assumed that an employee's value corresponds to his cost to an organization. This is only correct if the organization is not resource-constrained and has hired the optimal number of employees. If the value of the employee is higher than his costs, the estimated time is underrated; this is also called a "conservative" estimate. Secondly, and more importantly, the TSTS approach does not take into account how the saved time is used. Instead, it is implicitly assumed that saved time is efficiently reallocated among tasks which have to be done. In a study Rejers et al. have analyzed the various consequences saved time can have and the problems resulting from them [23]. Like the TSTS approach, the hedonic wage model [25][26] assumes that employees perform activities of different intrinsic value. Sassone differentiates between several work patterns that an employee has. The approach follows the assumption that in case of an IT-investment low-value-activities are replaced by more valuable tasks. Due to the higher number of high category activities a higher benefit ensues. The advantage of this method is the measurability of the benefit. But to measure it, extensive procedures (also for the first measurement of the initial status) are required and this characterizes the fundamental disadvantage of this approach. A further approach, the activity based costing [16], allocates the costs to products and services by assessing the costs of activities. This approach is similar to the costs of process approach, which assesses all activities in a process. This approach cannot be used for activities with a high variance of service time and if process cost data are not available. Therefore this approach is not practical for our considerations. The business process intelligence approach [6][10] has the objective of controlling the business process by using process execution data with the help of key performance indicators within a performance measurement system. A precondition for this approach is a high degree of IT integration to deliver the necessary data. In practice this precondition is seldom fulfilled. 
In addition to classic investment management and process-oriented approaches further methods to validate an investment exist. Pure cost-oriented approaches analyze the costs of IT investments, like the Zero Based Budgeting Approach [20], the Cost Effectiveness Analysis [26], Total Cost of Ownership [21], and the Target Costing Approach [27]. Strategic approaches [8] evaluate strategic aspects of an IT investment, like Porters competitive Five Forces Model [22], the approach of Nolan [17] and the approach of Parson [20]. To classify and compare IT investments several conceptual frameworks are used, like the Andresen Framework [2], the Pietsch Framework[20] and the EcoPOST Framework of Mutschler et al. [15]. Our approach does not only focus upon the costs, a strategic validation, or an overall assessment of the investment, but; the cost-benefit relation of the investment is a major aspect.

Secondly, some approaches deal with partial aspects of the profitability analysis, like the identification of the quantifiable benefit of automation of business processes. Choenni et al. [7] compare costs of a business process with the saving potential due to cycle time reduction before and after an implementation of a WFMS. This method can be used for less complex processes. The service time of such activities, like "applying for a job" or "request for vacation by employees", may not vary much. For complex business processes, e.g. IT solution design, this method is impracticable. All the activities have to be categorized according to different aspects in order to deal with the variance in service times. Reijers et al. [23] analyzed the performance of a business process using cycle time, waiting time, serving time and resource allocation. Case studies demonstrate a high reduction of cycle and serving time due to an automation by WFMS of administrative business processes of a public Dutch company. At first, an initial measurement of the status quo was executed. The results were simulated with basic conditions in the initial phase. A further simulation for the target state based on the same conditions was used for a comparison with a real data execution. Thus it was possible to create a simulation environment with the same conditions as the final state after implementation. This method leads to exceedingly correct results but it requires high efforts in measurement and simulation. For calculation purposes this method is too expensive and should only be used after an implementation.

\section{PROFITABILITY ANALYSIS}

\section{A. Overview}

This subsection comprehends an overview of the profitability analysis. Due to the economic potential determined in [11] a calculation of the quantitative benefit of each business process chosen for automation is possible. Qualitative benefits are considered later. The result of a selection of appropriate WFMS for the business processes $[13][3][5]$ makes the calculation of the costs of the automation of the chosen business processes possible. Hence a profitability analysis can be undertaken by comparing the costs and the quantitative benefits including also qualitative benefits. The result is a decision for or against an automation of selected business processes.

\section{B. Cost-Benefit Calculation and Decision Finding}

As mentioned in section 3 Becker et al. [4] present an approach for a cost-benefit calculation of IT investments that we use for our profitability analysis. This approach is characterized by the consideration of quantitative and qualitative benefits and is also easy to use in practice. This approach is used for each business process which has been evaluated; it takes the costs and benefits of IT projects into consideration. All costs like costs for hardware and software, costs for software development and implementation are described; moreover there is a differentiation depending on whether they occur just once or repeatedly. Once-only costs are normally depreciated for the lifespan and then added to the ongoing costs.

For our calculation we split the costs for hardware and software and also the costs for software development and implementation into costs of realization (costs of the workflow projects like customizing, building of interfaces, fulfilling testing scenarios), costs of infrastructure (to install and operate the infrastructure), costs for support and maintenance (including costs for user support after the implementation, also costs for bug-fixing) and costs for licenses (costs of purchase). This structure extensively simplifies the analysis of costs. The costs of infrastructure, costs for support and maintenance and the costs for licenses are then allocated to all selected workflows as depicted in figure 1 .

The costs of realization taken from figure 1 are determined by summing up all realization costs of each workflow project. The toal is $€ 340,000$. The costs of infrastructure, costs for support and maintenance, and the costs for licenses related to the first year of implementation are added, and that sum represents the auxiliary costs. These auxiliary costs are set into proportion to the realization costs for each business process. Accordingly the auxiliary costs (here $€ 85,000$ are set into relation to the realization costs of $€ 340,000$ and this results in a mark-up of $25 \%$. This markup of $25 \%$ has to be added to the realization costs of each business process. This leads to the total costs of each selected business process.

\begin{tabular}{|l|r|r|r|}
\hline Processes & $\begin{array}{c}\text { Realization } \\
\text { Costs }(€)\end{array}$ & Mark-Up $(€)$ & Total Cost $(\boldsymbol{\epsilon})$ \\
\hline Process 1 & 120,000 & 30,000 & 150,000 \\
\hline Process 2 & 70,000 & 17,500 & 87,500 \\
\hline Process 3 & 100,000 & 25,000 & 125,000 \\
\hline Process 4 & 50,000 & 12,500 & 62,500 \\
\hline Sum & $\mathbf{3 4 0 , 0 0 0}$ & & $\mathbf{4 2 5 , 0 0 0}$ \\
\hline
\end{tabular}

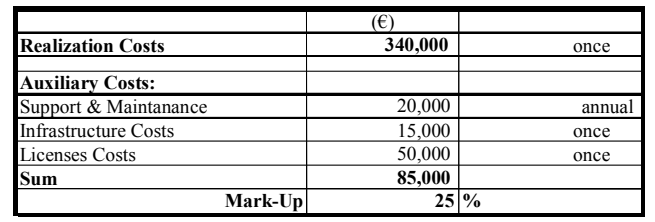

Figure 1. Cost calculation for workflow investment 
The benefits of an investment in IT [4] are separated into increase of profit (e.g. increase of profit due to investments in IT which makes it possible to enter a new market, increase of sales due to better delivery times), improvement in quality (e.g. reduction of mistakes and defects) and rationalization / reduction of costs (e.g. staff savings, increased productivity). The benefits gained by an increase in profit and the improvement in quality are often impossible to quantify, whereas benefits due to rationalization / reduction of costs are easier to quantify. We used the time savings time salary (TSTS) approach (as explained in section 3) for the quantification of the economic potential due to rationalization / reduction of costs. This approach is easy to handle and it leads to a "conservative" estimate (the estimated time is underrated). We adopted this approach for our considerations. We did not calculate the time savings related to each activity of a process or the whole process, we calculated the time savings of each cost unit participating in the process. This procedure was appropriate for our practice. Since the salaries of the employees do not vary much, we were able to calculate the average salary costs (the same as the costs of the personnel). Moreover this helps us to overcome the practical difficulty of having to estimate the time savings of individual activities, which is sometimes impossible, particularly in case of activities with a high variance of service times. As we have seen in our case studies, a cumulative estimate of time savings for each cost unit is much easier to achieve and more realistic. The estimation of time savings takes several aspects into account, e.g. the availability of all information at the start of an activity, and the transparency of the process status for precise escalation management. Thus the time savings of a business process in case of automation can be quantified by estimating all time savings over all cost units using the average cost rate of salary. The calculation of the quantitative benefit is shown in figure 2 .

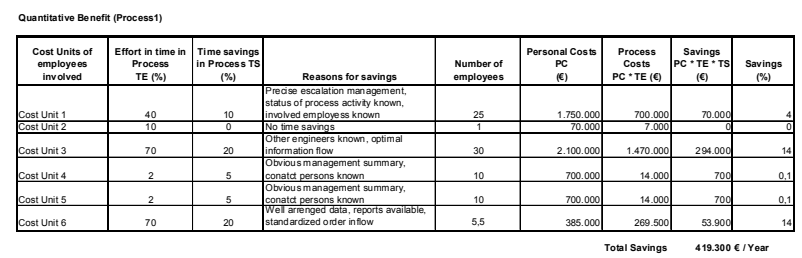

Figure 2. Calculation of the quantitative benefit for workflow investment

The calculation of the quantitative benefit shown in figure 2 is done in several steps. The names of the cost units of the employees involved are registered in the first column "Cost units of employees involved". The column "Effort in time in Process" (TE) describes the estimated time, which the employees are working in this process in a year. For estimating the column "Time savings in Process" (TS) the "reasons for savings" have to be listed first. Then the value for the savings has to be estimated (It is easier to estimate the savings in a week and then extrapolate them to get the result for a whole year). The next step is shown in the column "Number of employees", where the head count of each cost unit is captured. The following steps are calculations. The "personal costs" (PC) are calculated by multiplying the average cost rate of salary in one year by the number of employees. The personal costs (PC) multiplied with the effort in time in process (TE) results in the "costs of process", the (quantified) savings (in Euro) are calculated by multiplying the process costs with the time savings in process (TS). The addition of theses savings is shown as total savings (in Euro).

These potential time savings can be calculated, but certain preconditions need to be met for the traceability after implementation. There are some reasons for this. After the automatisation a low potential of time savings can no longer be detected because the time saved is then used for other activities, or the employees do not perceive the time savings at all. Reijers et al. [23] and Rosemann/Uthmann [24] have analyzed the different effects of saved time and the resulting consequences.

To obtain an indicator for traceable (and therefore transparent) time savings we do not want to use extensive calculation and measurement procedures (contrary to [18][23]). Therefore we use the column "Savings (\%)", which describes a measurement for the time savings related to one cost unit per year. We assume that time savings are only traceable if at least one part-time employee (working $50 \%$ of the time, that means 0.5 employee) can be saved. To reduce the head count by one part-time employee $(0.5$ employee), the savings (\%) of one cost unit multiplied by the number of employees in this cost unit have to exceed the value of 0.5 . Further perceptible savings are possible in steps of 0.5 employees. If we assume that a cost unit contains (on average) 8 employees (observed in the IT-Company, this number of employees often occurred in operative areas) a saving of about $7 \%$ leads to a saving potential of 0.56 employees. That corresponds to one part-time employee $(0.5$ employee). If the saving would be more than $14 \%$, the saving potential would be one full-time employee. Thus the marginal step value of 0.5 employee makes it possible to easily trace time savings. Our approach measures the time savings via savings in personnel, therefore no measurement of cycle times and service time prior to and after automation is necessary. The advantages of this approach are the ease of calculation, the traceability of the savings, and also a simple procedure in case of little IT integration which helps to avoid significant measurement efforts before automation.

There are different opportunities to use this now available potential. The employees can be made redundant, or take on additional work, or the number of executions of a process can be increased. Especially the two last opportunities are helpful to cope with the increasingly tight resource situation in industry.

Having explained the calculation of the costs and quantifiable benefits, both aspects are compared in a costbenefit analysis, also called profitability analysis for workflow management. The cost-benefit calculation model is depicted in figure 3.

The cost-benefit calculation model compares the costs and the quantifiable benefits in each period. In IT the time of amortization was about five to seven years in practice. 


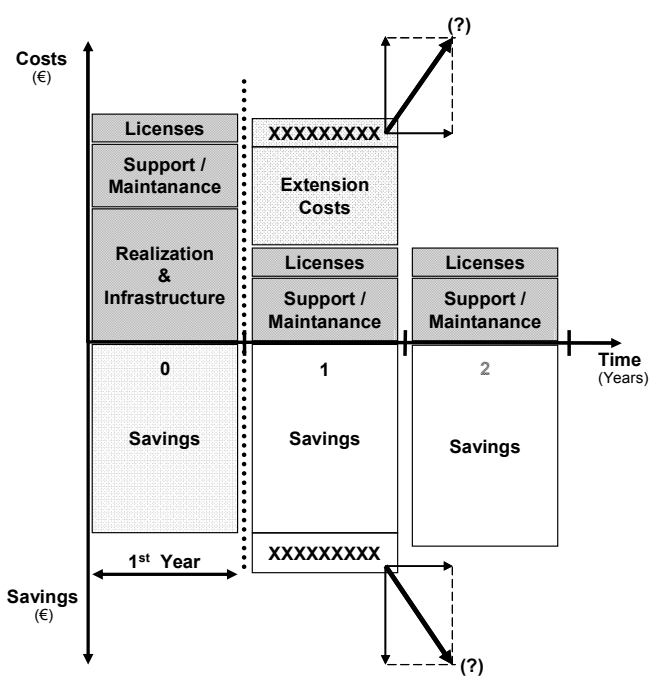

Figure 3. Cost-benefit calculation model

Rapid changes in time to market of IT technologies reduced the time of return on investment. Therefore the actual time on investment is about three to five years. Anyway, in case that the amortization time spans over multiple years a dynamic investment calculation with a consideration of the actual cash value has to be used.

Our long time experience in the operation of workflow management leads us to the conclusion that all automated processes have to be significantly changed or adapted after one year of use. Due to permanent changes in the company's environment and structure, an automated process cannot be considered resistant to changes that lead to significant costs. Thus, it is hard to predict the cost- and saving-trend of the following years after implementation (before an automation of a business process). Therefore we recommend an amortization time of one year. In other words, the automation of a business process has to be amortized within a year. This leads to the use of static investment calculations without a consideration of the actual cash value. Thus this approach makes the highest demands on the profitability of the automation: the period under consideration is limited to one year and the calculation of the savings follows a "conservative" approach. In all likelihood, processes which actually meet these tough demands will indeed provide the calculated benefits after the automation.

After calculating the costs and savings (quantitative benefits) for the first year, it is possible to make a decision about the investment in the automation of each business process by balancing the arguments (qualitative benefit)[4] as depicted in figure 4.

For the decision making procedure it is advisable to first of all deduct the (quantitative) savings from the total cost. Then it is necessary that the qualitative benefits are at least as high as the remaining costs. It it entirely up to the decision maker whether he/she thinks that the qualitative benefits compensate for the remaining costs and whether this is enough to recommend an investment in automation. If one makes a decision about an investment it is absolutely necessary to consider qualitative benefits, too.

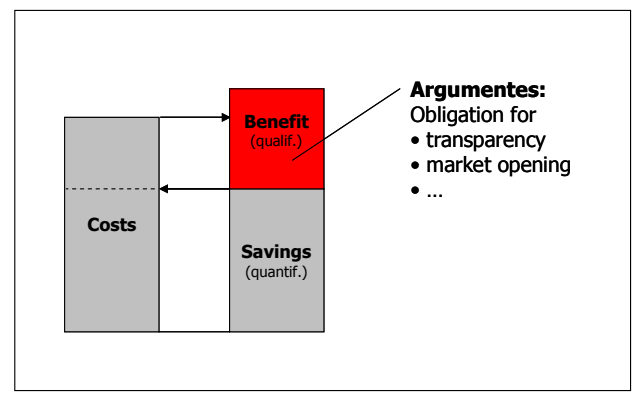

Figure 4. Profitability analysis via argument balance

\section{Executing the Method}

The profitability of automation was analyzed for five business processes in this company. Figure 5 presents the result of the investigation. The first column shows the business processes which were analyzed. The second column shows the category; " $\mathrm{v}$ " stands for a value creating process and "a" for an administrative process. The next column shows the cost-benefit balance, and the last column describes the qualitative benefits in case of automation.

\begin{tabular}{|c|c|c|c|}
\hline Process & Category & $\begin{array}{c}\text { Cost-Benefit } \\
\text { Balance }(€) \\
\end{array}$ & Qualitative Benefit \\
\hline Proposals & $\mathrm{v}$ & 114.200 & \begin{tabular}{|l} 
* Need of of transparency \\
$*$ Willingness to provide information
\end{tabular} \\
\hline Server installation & $\mathrm{v}$ & 38.410 & \begin{tabular}{|l|} 
*Need of transparency \\
* Willingness to provide documentation \\
\end{tabular} \\
\hline Relocation & $\mathrm{a}$ & -11.270 & \begin{tabular}{|l|} 
* Reduction of failure rates \\
* Process stability \\
* Need of data \\
\end{tabular} \\
\hline Order creation & $\mathrm{a}$ & -32.500 & \begin{tabular}{|l|}
$\begin{array}{l}* \\
\text { Nilling of transparency for } \\
* \\
* \text { Obligation of documentation }\end{array}$ \\
\end{tabular} \\
\hline Investment order generating & $\mathrm{a}$ & -27.300 & $\begin{array}{l}\text { * Need of transparency for } \\
\text { investment purposes } \\
\text { * Process standardizing } \\
\text { * Introduce the technology to the } \\
\text { top management }\end{array}$ \\
\hline
\end{tabular}

Figure 5. Result of the investigation

Despite the fact that only a comparatively short period of one year was considered and a conservative calculation, the value creating process offers a high degree of profitability. This also showed in several departments of the company due to changed human resource allocation. However, in the case of administrative business processes quantitative benefits need to be considered for an assessment of the investment.

\section{CONCLUSION AND FURTHER WORK}

In this paper we present a method for the evaluation of the investment into the automation of business processes by WFMS. The profitability analysis allows the management to make a decision about the investment. We presented a method for the calculation of the costs and the determination of the quantitative benefits of an automation based on quantitative benefits and costs. In this approach the costs have been divided into direct costs and auxiliary costs. Auxiliary costs are allocated proportionally to the direct costs. To calculate the quantitative benefit the time saving time salary (TSTS) approach was used; we did not calculate the time savings related to each activity of a process or for the whole process, we calculated the time savings of each 
cost unit which was part of the process. This approach allowed a simple calculation of time savings by means of a modified human resource allocation. Given our long experience the period under consideration was limited to one year; all automated processes change within a year after implementation which leads to a change in cost- and benefitaspects. Furthermore, the calculation of the savings followed a "conservative" approach (the estimated time is underrated). Thus this approach makes the highest demands on the profitability of the automation. The following profitability analysis with the help of balanced arguments which takes qualitative benefits into consideration makes it possible to decide whether or not to invest in the automation of business processes with the help of WFMS. In summary, this calculation method ensures a transparent and reproducible evaluation which can be done with little effort.

This calculation method for analyzing the profitability of automation was assessed in an empirical study in the IT Company by considering five automated business processes. The time saving potentials were calculated on the basis of several assumptions. The tests led to two statements: value creating processes require a lot of effort to be realized and are therefore expensive but they offer a high degree of profitability and meet the highest requirements regarding the profitability of automation. Administrative business processes offer little quantitative benefit and do not achieve profitability, the realization can also be expensive (dependent on the chosen WFMS). It is necessary to consider quantitative benefits for an assessment of the investment.

Some of the next steps will be to prove the validity of the method in other companies in different industries. Several case studies will be conducted.

\section{REFERENCES}

[1] Adams, J., Juleff, L., "Managerial Economics for Decision making", Palgrave Macmillan, 2003

[2] Andresen, J. L., "A Framework for Selecting an IT Evaluation Method - In the Context of Construction". PhD Thesis, Technical University of Denmark, Lyngby, Denmark, 2001

[3] Aversano, L.; Canfora, G.; De Lucia, A.; Gallucci, P.: "Business process reengineering and workflow automation: a technology transfer experience". Journal of Systems and Software 63, 2002, pp. $29-44$

[4] Becker, M., Haberfellner, R., Liebetrau, G., Vössner, S.: „EDVWissen für Anwender. Das Informatik-Handbuch für die Praxis“. Verlag Industrielle Organisation, Zürich 2004, pp. 294-340

[5] Berger, M.; Ellmer, E.; Quirchmayr, G.; Zeitlinger, A.: "Evaluating workflow management systems". Proceedings of the 8th International Workshop on Database and Expert Systems Applications, IEEE Computer Society, 1997, pp. 412-417

[6] Casati, F., Dayal, U., Sayal, M., Shan, M.-C., "Business Process Intelligence". HP Technical Report, 2002

[7] Choenni, S., Bakker, R., Baets, W.: "On the Evaluation of Workflow Systems in Business Processes". Electronical Journal of Information systems Evaluation 6(2) (2003) 33-44

[8] Clemons, E. K., "Evaluation of Strategic Investments in Information Technology", Communications of the ACM, 34(1), pp.22-36, 1991
[9] Copeland, T., Koller, T., Murrin, J., „Unternehmenswert - Methoden und Strategien für eine wertorientierte Unternehmensführung", Campus Verlag, Frankfurt / New York, 1998

[10] Grigori, D., Casati, F., Castellanos, M., Dayal, U., Sayal, M., Shan, M.-C., "Business Process Intelligence". Computers in Industry, 53(3), pp.321-343, 2004

[11] Gruber, H.; Huemer, C.: "Selecting business processes for automation by WFMS: An Evaluation Framework". Proceedings of 7th BIR Conference 2008, pp. 77-92

[12] Hoffmeister, W., „Investitionsrechnung und Nutzwertanalyse - Eine entscheidungsorientierte Darstellung mit vielen Beispielen und Übungen“, Kohlhammer, 2000

[13] Müller, J.: "Workflow-based Integration". Springer, Berlin/Heidelberg/New York 2005, pp. 190-194

[14] Murphy, K. E., Simon, S. J., "Using Cost Benefit Analysis for Enterprise Resource Planning Project Evaluation: A Case for including Intangibles", Proceedings of 34th Hawaii Int'l. Conf. on System Sciences (HICSS '01), 2001

[15] Mutschler, B., Bumiller, J., Reichert, M.: "Designing an economicdriven evaluation framework for process-oriented software technologies". In: 28th International Conference on Software Engineering (ICSE 2006), Shanghai, China, May 20-28, 2006. (2006) $885-888$

[16] Mutschler, B., Zarvic, N., Reichert, M., "A survey on economicdriven Evaluations of Information technology", Tech. Report TRCTIT-07-21, Centre for Telematics and Information (CTIT), University of Twente, 2007

[17] Norton, D. P., "Stage by Stage - Letter to Management. The Economics of Computing in the Advanced Stages", 1981

[18] Oba, M., Onada, S., Komoda, N., "Evaluating the quantitative effects of workflow systems based on real cases". In: 33rd Hawaii international conference on system sciences (IEEE), Vol. 6 (p. 6031)

[19] Olfert, K., „Investition“, Khiel, 2003

[20] Pietsch, T., „Bewertung von Informations- und Kommunikationssystemen: Ein Vergleich betriebswirtschaftlicher Verfahren“, ESV (Erich Schmidt Verlag), 2003

[21] Pisello, T., IT "Value Chain Management - Maximizing the ROI from IT Investments: Performance Metrics and Management Methodologies Every IT Stakeholder Should Know", Alinean, LLC, 2003

[22] [22] Porter, M. E., "Competitive Strategy: Techniques for Analyzing Industries and Competitors". Free Press, 1998

[23] [23] Rejers, H. A., van der Aalst, W. M. P., "The effectiveness of workflow management systems: Predictions and lessons learned", International Journal of Information Management, 25, 2005, pp. 458472

[24] Rosemann, M., Uthmann, C., „Faktoren der Wirtschaftlichkeit von Workflow Management Anwendungen“, in: Workflow-Management in der industriellen Praxis, vom Buzzword zum High-tech-Instrument, Müller, B.F./Stolp, P. (Hrsg.), Berlin 1999

[25] Sassone, P. G., "Cost-Benefit Methodology for Office Systems", ACM Transactions on Office Information Systems, 5(3), pp.273-289, 1987

[26] Sassone, P. G., "Cost Benefit Analysis of Information Systems: A Survey of Methodologies", Proc. Int'l. Conf. on Supporting Group Work (GROUP '88), pp.73-83, Palo Alto, 1988

[27] Shank, J. K., Fisher, J., "Target Costing as a Strategic Tool", MIT Sloan Management Review, 41(1), 1999

[28] WFMC (Workflow Management Coalition): Document of understanding -1 . Objectives. http://www.wfmc.org/document-ofunderstanding.html

[29] zur Muehlen, M.: "Integrationsperspektiven des Workflowmanagements. In: Integrationsmanagement". Eds.: AugustWilhelm Scheer, et al., Münster, 1999, pp. 94-106. 